\title{
O vocabulário controlado do Governo Eletrônico: contribuições e limites na implementação da Lei de Acesso à Informação no Brasil
}

\author{
Janyluce Rezende Gama \\ Doutora; Universidade Federal do Espírito Santo, Vitória, ES, Brasil; \\ janylucegama@gmail.com \\ Georgete Medleg Rodrigues \\ Doutora; Universidade de Brasília, Brasília, DF, Brasil; \\ medleg.georgete@gmail.com
}

\begin{abstract}
Resumo: A Lei de Acesso à Informação, promulgada em 2011, introduziu um dispositivo permitindo que as solicitações de informação entrem por um único meio, independentemente do destinatário público. Esse sistema classifica os pedidos por meio de um vocabulário controlado que organiza e, teoricamente, facilitaria o processo para cidadãos e gestores públicos. Este artigo tem como objetivo verificar a contribuição e limites do vocabulário Controlado do Governo Eletrônico na implementação da Lei de Acesso à Informação no governo federal e é um recorte de uma pesquisa de doutorado em Ciência da Informação. Utilizou-se uma metodologia com abordagem qualitativa, que envolveu, na primeira etapa, uma pesquisa bibliográfica relacionada ao tema e o levantamento de informações sobre o vocabulário controlado do Governo Eletrônico, nas suas diversas versões, nos portais do governo federal, e, na segunda, uma consulta à Controladoria-Geral da União a respeito da estratégia de treinamento dos gestores públicos para o uso dessa ferramenta. Os resultados apontaram para um esforço por parte do governo federal em avançar na melhoria da classificação das funções de governo para classificar as demandas decorrentes da Lei de Acesso à Informação. Porém, consulta à ControladoriaGeral da União, além de informações obtidas com alguns gestores e outros dados empíricos da pesquisa de doutorado, mostrou os limites desses esforços quanto ao treinamento dos gestores públicos no uso dessa ferramenta de gestão.
\end{abstract}

Palavras-chave: Lei de acesso à informação. Linguagem controlada. Vocabulário controlado do Governo Eletrônico. Transparência. Administração pública.

\section{Introdução}

O volume de informação gerado pelas organizações nos dias atuais desafia os profissionais da informação no que diz respeito ao armazenamento, busca e 
recuperação da informação. Somente com a modernização dos instrumentos que auxiliam o tratamento da informação será possível adequar-se às rápidas mudanças no crescimento da importância do uso e da capacidade de recuperação da informação (ALMEIDA; SOUZA, 2011).

Durante as duas últimas décadas, a ampla adoção do gerenciamento eletrônico de dados em instituições trouxe a consciência da necessidade de ferramentas voltadas para a melhoria dos mecanismos de busca (SEVAROLLI; MENDES, 2013-2014). Diante disso, é fato que quando se fala em recuperação da informação deve-se ressaltar também a necessidade de uma estratégia de busca eficaz.

Segundo Lopes (2002, p. 46), em princípio, a forma exata de uma estratégia de busca é determinada pela natureza da base de dados a ser acessada e pela sua respectiva estrutura de informação, isto é, pela formatação de seus campos de identificação do documento e dos campos de identificação do conteúdo temático do mesmo. A identificação dessa estrutura de campos de busca implica o conhecimento da documentação básica fornecida pelos produtores das bases e pelos bancos de dados onde estão hospedadas.

Nesse contexto, um instrumento que tem recebido destaque para a recuperação de informações é o vocabulário controlado, um dos instrumentos previstos pelos sistemas de organização do conhecimento (SOC) como uma opção de controle terminológico. De fato, essa ferramenta - vocabulário controlado - objetiva organizar e recuperar documentos e informações com consistência, gerando, assim, confiança no sistema (SMIT; KOBASHI, 2003). O vocabulário controlado intervém na organização e nos pontos de acesso utilizando recursos que geram maior racionalização na recuperação informacional, minimizando, assim, os principais problemas do sistema: a duplicação e a dispersão de informações (SIQUEIRA, 2011).

O tema vocabulários controlados também tem recebido destaque internacional após a criação do Classification of the Functions of Government (COFOG), publicada pela Organização das Nações Unidas (ONU) para funções de governo. A partir daí, organizações tais como a Organização para a Cooperação e Desenvolvimento Econômico (OCDE), o Fundo Monetário 
Internacional (FMI) e a Comissão Europeia por meio da Eurostat, têm feito uso dessa ferramenta. O objetivo dessas organizações é criar um padrão de classificação para as atividades de governo, facilitando o uso tanto para usuários internos quanto externos do setor público em diversos países. O ganho com a padronização desses dados é que as contas de diferentes países referentes às funções de governo podem ser comparadas. (EUROSTAT, 2014; INTERNATIONAL MONETARY FUND, 2014; ORGANISATION FOR ECONOMIC CO-OPERATION AND DEVELOPMENT, 2011).

No Brasil, nos últimos anos, têm crescido os estudos em linguagem controlada em várias instituições públicas, porém com aplicação no uso de vocabulários especializados, elaborados para suprir as demandas dos órgãos para os quais foram desenvolvidos e não para a sociedade em geral. Exemplo disso são as pesquisas realizadas por Moraes et al. (2012); Almeida e Souza (2011); Narukawa (2011); Bacha e Almeida (2013); e Sevarolli e Mendes (2013).

Para o governo brasileiro, no entanto, o objetivo da adoção de uma linguagem controlada é facilitar aos cidadãos e gestores públicos a localização de informações independentemente do conhecimento de qual órgão é o responsável pelo assunto procurado e, provavelmente, também seguindo as tendências internacionais conforme citado anteriormente. Nesse sentido, na ultima década, surgiu a necessidade de se criar um vocabulário controlado voltado totalmente para o cidadão.

Esse desafio de desenvolver uma ferramenta de classificação no governo voltada para o cidadão foi detectado no estudo realizado por Jardim (2007), no período de maio de 2003 a março de 2005. A pesquisa apresentou a classificação, em categorias, adotada pelo governo federal para o Portal Rede Governo naquele período, e, como conclusão, o estudo destacava que os portais do governo geralmente não expressavam a perspectiva do cidadão, mas a do Estado. Ainda que em determinada situações os portais estivessem estruturados por temas, a classificação adotada, segundo Jardim (2007), mostrava-se mais próxima da lógica do Estado do que da sociedade. 
Nesse contexto, em 2010, surgiu no Brasil o vocabulário controlado do Governo Eletrônico (VCGE), ferramenta utilizada para indexar as diversas informações, como documentos, bases de dados, sites, portais, etc. do governo federal. Ele foi projetado com dois objetivos básicos: interface de comunicação com o cidadão e ferramenta de gestão. Como interface de comunicação com o cidadão, ele deveria indexar as informações de governo de uma forma simples e inteligível. Como ferramenta de gestão, deveria ajudar os gestores a gerenciarem suas informações (BRASIL, 2014a; RIBEIRO; PEREIRA, 2015).

Durante esse tempo, passando por várias nomenclaturas, o VCGE teve uma difusão restrita no governo, tendo sido usado por poucos órgãos e por curtos períodos. Porém, com a promulgação da Lei n. ${ }^{\circ} 12.527$, de 18 de novembro de 2011 (Lei de Acesso à Informação ou LAI) (BRASIL, 2011a), seu uso tornou-se obrigatório para todos os órgãos do Poder Executivo Federal e sua classificação passou a ser exigida no preenchimento do e-SIC, o Sistema de Informação ao Cidadão da Controladoria-Geral da União (CGU), que recebe os pedidos de informação aos órgãos do governo federal.

De cumprimento obrigatório para todos os entes governamentais, a Lei de Acesso à Informação produz impactos na gestão pública e exigirá, para sua efetiva implementação, a adoção de uma série de medidas por parte do governo e, dentre os diversos desafios que o país enfrenta na política de acesso à informação, destacam-se a falta de tecnologia, de preparação e treinamento dos servidores, de escolas de formação para as práticas básicas de gestão pública (BRASIL, 2011b; GARRIDO, 2012); além da falta de uma gestão de informação na administração pública (JARDIM, 2012); e das dificuldades estruturais e inclusão digital (GONTIJO, 2002).

Mas, o acesso à informação exige tanto a superação das dificuldades infraestruturais relativas ao desenvolvimento de novos sistemas, redes de telecomunicação e ao acesso democrático a elas, e, principalmente, à educação digital dos diversos usuários, isto é, a sua capacitação para usar e manejar os novos meios de comunicação (GONTIJO, 2002).

Nesse contexto, justifica-se buscar compreender mais adequadamente o papel do vocabulário controlado do Governo Eletrônico, de sua gênese à sua 
implementação, como ferramenta de auxílio do governo federal no contexto da implementação da Lei de Acesso à Informação no Brasil. Assim, esta pesquisa procura responder à seguinte questão: Quais são as contribuições e os limites do VCGE na implementação da Lei de Acesso à Informação na administração pública federal brasileira?

Este artigo é um recorte de uma pesquisa de doutorado e possui como objetivo identificar a contribuição e os limites do vocabulário controlado do Governo Eletrônico na implementação da Lei de Acesso à Informação na administração pública federal brasileira. Para isso, descreve a finalidade do VCGE na implementação da Lei de Acesso à Informação, sua evolução na administração pública brasileira, da primeira versão até a mais atual. Verificou, ainda, se o governo federal empreendeu ações no sentido de preparar os gestores públicos para a utilização dessa ferramenta.

Para tanto, como metodologia, utilizou-se uma abordagem qualitativa, que envolve, na primeira etapa, a pesquisa bibliográfica referente ao tema, e, na segunda, o levantamento de informações, nos portais do governo federal brasileiro, relacionadas ao VCGE, além de consulta à CGU por meio do seu eSIC. Os portais pesquisados para o levantamento de informações para este artigo foram: Acesso à Informação (2017), Governo Eletrônico (2017), Ministério da Transparência e Controladoria-Geral da União (2017), Portal Brasil (2017), Portal da Transparência (2017), Repositório de Vocabulários e Ontologias do Governo Eletrônico (2017).

\section{Referencial teórico e debates acerca da aplicação prática, as vantagens e desvantagens do uso de vocabulários controlados}

Nesta seção, são apresentados os principais autores que guiaram esse estudo no entendimento conceitual de "vocabulário controlado" dentro do sistema de organização do conhecimento (SOC), ao mesmo tempo em que são destacados aspectos, dentro de uma revisão de literatura, da aplicação prática e as vantagens e desvantagens do uso do vocabulário controlado.

Para os objetivos deste artigo, gostaríamos de reter a definição de vocabulário controlado de Lancaster $\left(2004^{1}\right.$, p. 19 apud SILVA; DODEBEI, 
2016), que seria "essencialmente uma lista de termos autorizados" com a finalidade, nas palavras de Silva e Dodebei (2016), de "[...] controlar sinônimos, diferenciar homógrafos e estabelecer as relações hierárquicas e não hierárquicas." (DODEBEI, 2016, p. 6).

Segundo Smit e Kobashi (2003), o controle de vocabulário foi, inicialmente, desenvolvido pela Documentação e introduziu-se na arquivística, especialmente em razão da informatização crescente dos arquivos. Siqueira (2011), por sua vez, observa que o estudo do vocabulário controlado ainda é escasso na área arquivística, e tal fato se justificaria por duas razões. A primeira, é que se trata de um recurso recente na área, já que os estudos nessa área se concentram no final do século XX; e a segunda, pela falta de divulgação das experiências existentes com o uso desses vocabulários controlados, grande parte em empresas privadas, dificulta o estabelecimento de paradigmas e metodologias de utilização do recurso.

Estudos recentes foram encontrados na área de linguagem controlada com aplicações em vocabulários especializados e estão apresentados no Quadro 1. São exemplos:

Quadro 1 - Estudos realizados na área de Linguagem Controlada

\begin{tabular}{|c|l|}
\hline Autores & \multicolumn{1}{|c|}{ Objetivo do estudo e local de aplicação } \\
\hline $\begin{array}{c}\text { Moraes et al. } \\
(2012)\end{array}$ & $\begin{array}{l}\text { Estudo realizado no Sistema Integrado de Bibliotecas da Universidade de } \\
\text { Sesenvolvimento de um plano de inovação para o seu Vocabulário } \\
\text { Controlado, relatando suas pretensões e ações definidas para concretizá-las. }\end{array}$ \\
\hline $\begin{array}{c}\text { Almeida e } \\
\text { Souza (2011) }\end{array}$ & $\begin{array}{l}\text { Este estudo analisa o Vocabulário Controlado FINEP (VCF) enquanto } \\
\text { instrumento de organização e representação da informação nas propostas de } \\
\text { financiamento. Tem como objetivo investigar a viabilidade de aplicação do } \\
\text { processo de categorizçãa dos descritores em uso como contribuição para } \\
\text { avaliação e reestruturação do vocabulário. }\end{array}$ \\
\hline $\begin{array}{c}\text { Narukawa } \\
(2011)\end{array}$ & $\begin{array}{l}\text { O estudo investiga a atuação de vocabulário controlado a partir da análise } \\
\text { dos resultados de aplicação do vocabulário ThesAgro no Sistema de } \\
\text { Indización SemiAutomatica (SISA), com objetivos de identificar as } \\
\text { características que definem e distinguem os tipos de vocabulários; analisar } \\
\text { propostas metodológicas e sistemas de indexação; e aplicar o ThesAgro no } \\
\text { sistema SISA em análise comparativa com a indexação manual da } \\
\text { Biblioteca Nacional de Agricultura (BINAGRI). }\end{array}$ \\
\hline $\begin{array}{c}\text { Bacha e } \\
\text { Almeida (2013) }\end{array}$ & $\begin{array}{l}\text { Estudo sobre a experiência do repositório institucional da FGV. Propõe a } \\
\text { utilização das linguagens natural e controlada como forma de melhoria da }\end{array}$ \\
\hline
\end{tabular}




\begin{tabular}{|c|l|}
\hline & $\begin{array}{l}\text { pesquisa por assunto dentro de um repositório digital. Tem como objetivo } \\
\text { traçar um paralelo entre as atribuições de assuntos feitas em bibliotecas } \\
\text { tradicionais e repositórios digitais. }\end{array}$ \\
\hline Sevarolli e & $\begin{array}{l}\text { Pesquisa voltada para a coleção fotográfica do Arquivo Histórico de São } \\
\text { Paulo, unidade da Secretaria Municipal de Cultura. Objetiva estabelecer } \\
\text { parâmetros para o gerenciamento de um vocabulário controlado que } \\
\text { refletisse a natureza de um arquivo público, expressão das ações da } \\
\text { municipalidade no gerenciamento da cidade. }\end{array}$ \\
\hline
\end{tabular}

Fonte: Elaborado pelas autoras com base nos estudos citados.

$\mathrm{O}$ aumento no volume de documentos produzidos e armazenados nas organizações (públicas e privadas) e a necessidade cada vez maior de recuperação rápida e precisa das informações mostram que a solução passa, forçosamente, por uma classificação rigorosa (SMIT; KOBASHI, 2003).

Moraes et al. (2012) afirmam que os vocabulários controlados são ferramentas de representação de informação necessárias para padronizar a descrição de conteúdos e a classificação da informação, tornando os sistemas de informação mais consistentes e também minimizando a dispersão de informação, tanto no momento do armazenamento quanto da recuperação.

Entretanto, apesar das vantagens desses vocabulários controlados, estes também apresentam desvantagens. Para Moraes et al. (2012), um dos pontos mais críticos dos vocabulários controlados é a necessidade de permanente atualização, que engloba a constante revisão e atualização da terminologia existente no vocabulário e a vigilância permanente sobre o sistema computacional que dá suporte ao vocabulário. Esses dois pontos podem ser entendidos como os principais pilares no desenvolvimento e manutenção de um vocabulário controlado atualizado e de qualidade.

Segundo Lopes (2002), outro ponto crítico é que, uma vez que não existe padronização ou compatibilidade entre os diferentes vocabulários, mesmo naqueles que são específicos de um determinado assunto, o mesmo conceito pode ser designado por termos diversos nos distintos vocabulários.

O desenvolvimento de linguagens controladas para indexação e recuperação da informação requer ainda trabalho em equipe, altos investimentos e tempo para gerar, testar e sedimentar um instrumento de trabalho que deve ser continuamente atualizado (LOPES, 2002). 
As vantagens e desvantagens no uso do vocabulário controlado são apresentadas no Quadro 2 a seguir:

Quadro 2 - Vocabulário controlado: vantagens e desvantagens

\begin{tabular}{|l|l|}
\hline \multicolumn{1}{|c|}{ Vantagens } & \multicolumn{1}{|c|}{ Desvantagens } \\
\hline $\begin{array}{l}\text { 1. Controle total do vocabulário de indexação, } \\
\text { minimizando os problemas de comunicação } \\
\text { entre indexadores e usuários. }\end{array}$ & $\begin{array}{l}\text { Custos: a produção e manutenção da base de } \\
\text { dados terão despesas maiores com a equipe de } \\
\text { indexadores. Será necessário ainda manter } \\
\text { pessoal especializado na atualização do } \\
\text { thesaurus. }\end{array}$ \\
\hline $\begin{array}{l}\text { 2. Com o uso de um thesaurus e suas } \\
\text { respectivas notas de escopo, os indexadores } \\
\text { podem assinalar mais corretamente os } \\
\text { conceitos dos documentos. }\end{array}$ & $\begin{array}{l}\text { O vocabulário controlado poderá não refletir } \\
\text { adequadamente os objetivos do produtor da } \\
\text { base, caso esteja desatualizado. }\end{array}$ \\
\hline $\begin{array}{l}\text { 3. Se bem constituído, o vocabulário } \\
\text { controlado poderá oferecer alta recuperação e } \\
\text { relevância e, também, ampliar a confiança do } \\
\text { usuário diante de um possível resultado } \\
\text { negativo. }\end{array}$ & $\begin{array}{l}\text { Um vocabulário controlado poderá se distanciar } \\
\text { dos conceitos adequados para a representação } \\
\text { das necessidades de informação dos usuários. }\end{array}$ \\
\hline $\begin{array}{l}\text { 4. As relações hierárquicas e as remissivas do } \\
\text { vocabulário controlado auxiliam tanto o } \\
\text { indexador, quanto o usuário na identificação } \\
\text { de conceitos relacionados. }\end{array}$ & $\begin{array}{l}\text { Necessidade de treinamento no uso dos } \\
\text { vocabulários controlados, tanto para os } \\
\text { intermediários quanto para os usuários finais. }\end{array}$ \\
\hline $\begin{array}{l}\text { 5. Redução no tempo de consulta à base, pois } \\
\text { a estratégia de busca será mais bem elaborada } \\
\text { com o uso do thesaurus. }\end{array}$ & $\begin{array}{l}\text { Desatualização do vocabulário controlado } \\
\text { poderá conduzir a falsos resultados. }\end{array}$ \\
\hline
\end{tabular}

Fonte: Lopes (2002).

Por fim, além dos estudos já citados nesse tópico com vocabulários especializados, foi encontrada uma pesquisa recente realizada por Ribeiro e Pereira (2015) com objetivo de analisar a classe sobre Previdência Social do VCGE investigando a publicação de dados governamentais abertos, realizada pela Empresa de Tecnologia e Informações da Previdência Social. A pesquisa conclui que a utilização do VCGE pode ir além de um mapa para navegação em páginas eletrônicas do setor público brasileiro, constituindo instrumento dinâmico de organização do conhecimento, podendo ser utilizado para diversos fins, de acordo com os interesses de cada usuário.

Assim, considerando os autores estudados acima, para os objetivos deste artigo, interessa reter o seguinte: (1) o vocabulário controlado é entendido, aqui, 
como um instrumento de representação da informação; (2) apesar das desvantagens desse instrumento enumeradas no Quadro 2, as suas vantagens são bastante significativas, especialmente no que diz respeito à sua capacidade de, se bem constituído, oferecer alta possibilidade de recuperação e relevância das informações, bem como ampliar a confiança do usuário diante de um possível resultado negativo. Em se tratando de buscar a contribuição de um vocabulário controlado para a aplicação da Lei de Acesso à Informação, esse segundo aspecto é muito importante.

Por último, sinalizando os limites do vocabulário controlado, uma pesquisa realizada por Jardim (2013) identificou que é nas categorias ensino superior, mestrado e doutorado que se concentram $68 \%$ dos solicitantes pessoas físicas. O que pressupõe uma forte correlação entre o nível educacional dos solicitantes e os diversos fatores que levam o cidadão a demandar acesso à informação governamental. Quanto maiores os níveis de exclusão informacional do cidadão, em decorrência da pouca instrução, parecem menores as condições de uso da Lei de Acesso à Informação por esse grande segmento da sociedade brasileira.

\subsection{Vocabulário controlado do Governo Eletrônico: contexto histórico}

Os vocabulários controlados atuam como instrumentos que minimizam os ruídos na comunicação entre os sistemas de informação e seus usuários, sendo importantes instrumentos auxiliares no processo de organização, representação e recuperação da informação. Considerando-se a perspectiva mediadora dos arquivos, acredita-se que, sem o recurso da padronização terminológica na representação documentária, prejudica-se o fluxo de comunicação. Na ausência de controle terminológico por meio de linguagem documentária, isso é, sem a adoção de procedimentos de desambiguação da linguagem natural, realiza-se um uso pobre da linguagem em si, enquanto elemento capaz de sintetizar e sistematizar conceitos.

Vários sistemas de recuperação de informação oferecem o acesso a múltiplas bases de dados, e, para cada área do conhecimento humano, existem várias bases de dados. Entretanto, cada base utiliza o seu próprio vocabulário 
controlado (LOPES, 2002). Na área governamental não é diferente. Abrangendo diversas áreas do conhecimento humano, a administração pública brasileira possui diferentes tipos de vocabulários controlados, nas diversas instâncias do Estado, isto é, o Poder Executivo, Legislativo e Judiciário.

O aumento na demanda por informações públicas fez com que o governo brasileiro também se preocupasse com a linguagem controlada para facilitar a busca e recuperação por suas informações. Atualmente, já é consenso que os recursos informacionais do governo constituem valiosos ativos econômicos. $\mathrm{Na}$ percepção do próprio governo, ao garantir que a informação governamental possa ser rapidamente localizada e transmitida entre os setores público e privado, mantidas as obrigações de privacidade e segurança, o governo auxilia no aproveitamento máximo deste ativo, impulsionando e estimulando a economia do país (BRASIL, 2014a; RIBEIRO; PEREIRA, 2015).

A primeira definição de uma lista de termos no governo federal brasileiro, de âmbito geral, foi a Lista de Categorias de Governo (LCG), divulgada em março de 2004, como uma lista que contemplava todos os assuntos relacionados com a atuação de governo. Dois anos depois, em 2006, a denominação da lista mudou para Lista de Assuntos de Governo, LAG, com um foco em taxonomia de navegação (BRASIL, 2011c).

Em novembro de 2010, o VCGE entrou em consulta pública, sendo publicado em março de 2011. Sob a responsabilidade do Ministério do Planejamento, Orçamento e Gestão, por meio da Secretaria de Logística e Tecnologia da Informação (MP/SLTI). Ao longo desse tempo, o VCGE, com suas várias denominações, teve uma difusão restrita no governo. Foi usado por poucos órgãos e por curtos períodos e mantido por grupos de voluntários e indicados pelos órgãos (BRASIL, 2011c).

A elaboração do VCGE foi inspirada no Manual Técnico de Orçamento (MTO), e na Classificação das Funções do Governo (COFOG), uma classificação publicada pela ONU, para funções de governo. A classificação orçamentária do governo brasileiro, descrita no MTO, é conhecida como Portaria $\mathrm{n}^{\circ}$ 42, de 14 de abril de 1999, por ter sido essa uma das portarias que a reformulou. Esta estabeleceu a classificação das despesas por função e 
subfunção, vigente até os dias de hoje e obrigatória para a União, Estados e Municípios (BRASIL, 1999).

Já a classificação das funções do governo, abreviada como COFOG, foi desenvolvida na sua versão atual, em 1999, pela OCDE e publicada pela Divisão de Estatística da ONU como um padrão de classificação dos efeitos das atividades de governo. A classificação tem três níveis de detalhe: divisões, grupos e classes (EUROSTAT, 2014).

O primeiro nível da classificação das funções do governo, COFOG, que divide os dados de despesa em dez grupos funcionais ou subsetores de despesas, tais como a defesa, educação e proteção social, é denominado de divisão. Já o segundo nível possui mais divisões para cada grupo de primeiro nível em até nove subgrupos (ORGANISATION FOR ECONOMIC CO-OPERATION AND DEVELOPMENT, 2011). A classificação COFOG é dividida até o terceiro nível de detalhamento, que é denominado classe.

Segundo Nogueira e Cavalcante (2010), a classificação das funções do governo foi adotada como um padrão em contas nacionais e suas dez divisões correspondem aos principais objetivos (funções) de governo, enquanto os grupos e classes detalham os meios para que os objetivos de governo sejam atingidos.

Assim, com a inspiração dessas fontes na evolução do VCGE, pode-se afirmar que ele foi projetado com dois objetivos básicos: interface de comunicação com o cidadão e ferramenta de gestão. Como interface de comunicação com o cidadão, ele deve indexar as informações de governo de uma forma simples e inteligível. Como ferramenta de gestão, ele deve ajudar aos os gestores a gerenciarem suas informações (BRASIL, 2014a).

De acordo com Ribeiro e Pereira (2015), pode-se inferir que o VCGE utilizou a linguagem do leigo, ou seja, uma linguagem livre e preocupada com o uso comum mais do que com a precisão acadêmica. Segundo esses autores, vislumbra-se que a utilização deste vocabulário controlado pode ir além de um mapa para navegação em páginas eletrônicas do setor público brasileiro. Seu uso pode ser estendido a outros propósitos, como, por exemplo, ser utilizado pelo Estado para representação do domínio do mapa conceitual, de cada setor 
público, mostrando sua trajetória ao longo do tempo, ou pode ser usada pelos cidadãos para descrição, recuperação e reutilização de informações governamentais (RIBEIRO; PEREIRA, 2015).

\subsection{A Lei de Acesso à Informação e o vocabulário controlado do Governo}

\section{Eletrônico}

Um dos principais avanços da Lei de Acesso à Informação, aprovada em novembro de 2011, encontra-se no caput de seu art. $3^{\circ}$, o qual prevê que os procedimentos previstos na Lei “[...] destinam-se a assegurar o direito fundamental de acesso à informação e devem ser executados em conformidade com os princípios básicos da administração pública [...]”. Dentre as diretrizes que orientam a Lei, o inciso I do referido artigo, está a “[...] observância da publicidade como preceito geral e do sigilo como exceção [...]" (BRASIL, 2011b, doc. eletrônico).

A Lei de Acesso à Informação veio, na verdade, regulamentar o direito de acesso à informação pública previsto na Constituição Federal de 1988, no artigo $5^{\circ}$, inciso XXXIII do Capítulo I - dos Direitos e Deveres Individuais e Coletivos - que dispõe que:

[...] todos têm direito a receber dos órgãos públicos informações de seu interesse particular, ou de interesse coletivo ou geral, que serão prestadas no prazo da lei, sob pena de responsabilidade, ressalvadas aquelas cujo sigilo seja imprescindível à segurança da sociedade e do Estado. (BRASIL, 1988, p. 3).

A Constituição também tratou do acesso à informação pública em seu art. $5^{\circ}$, inciso XIV, art. $37, \S 3^{\circ}$, inciso II e no art. $216, \S 2^{\circ}$, dispositivos esses que a Lei de Acesso à Informação regulamenta, estabelecendo requisitos mínimos para a divulgação de informações públicas e procedimentos que visam facilitar o seu acesso por qualquer pessoa, conforme explicitado pela Controladoria-Geral da União (BRASIL, 2013a), órgão que tem um papel fundamental nesse processo, como veremos mais adiante.

Mas, somente dispositivos legais não são suficientes para o sucesso da implementação de uma política de acesso à informação. Na maioria dos países, existe uma cultura arraigada de sigilo no âmbito do governo. $\mathrm{O}$ direito à 
informação depende, em última análise, da mudança desta cultura já que é praticamente impossível forçar os servidores públicos a se mostrarem abertos, mesmo com as legislações mais progressistas. Em vez disso, o sucesso, no longo prazo, depende do convencimento dos funcionários públicos de que a abertura não é apenas uma obrigação indesejada, mas também um direito humano fundamental e essencial para a governança efetiva e apropriada (MENDEL, 2008).

Uma pesquisa realizada pela Controladoria-Geral da União (BRASIL, 2011b) permite perceber certa dose de desconfiança e receio entre os servidores públicos federais quanto ao uso que os solicitantes podem fazer das informações solicitadas, o que pode gerar situações em que as informações são exageradamente concentradas nas mãos de determinados indivíduos ou setores, além disso, na referida pesquisa foi apontado que a prestação de informações poderá comprometer a capacidade dos órgãos de bem desempenhar as atribuições que lhe são próprias e precípuas.

Propiciar amplo acesso à informação exige resolver problemas estruturais, incluindo o tratamento e a organização das informações, mas, também exige esforços para a educação digital dos usuários, isto é, a sua capacitação para usar e manejar os novos meios de comunicação (GONTIJO, 2002). Sem a adoção dessas ações, apenas a disponibilidade de informações não habilita a sociedade a exercer um efetivo controle social.

Resolver o problema das dificuldades infraestruturais é incluir a sociedade na deliberação das novas políticas públicas. Segundo Speck (2002), o acesso às informações públicas é imprescindível para uma prática mais dialógica e interativa da definição e deliberação de políticas públicas. Em geral, os órgãos públicos temem discussões abertas com a população e a sociedade civil organizada. Os servidores públicos, segundo esse autor, inibem a livre circulação de informações porque temem críticas e obstrução a seus projetos por parte da sociedade.

Outro aspecto relatado na pesquisa da Controladoria-Geral da União (BRASIL, 2011b) que parece explicar a não disponibilização das informações públicas é que o controle das informações, especialmente dos bancos de dados, 
cria um status diferenciado e garante o espaço político dos técnicos dentro de seus órgãos. Por isso, há resistência em disponibilizar informações não só para a sociedade em geral, mas às vezes até para outras áreas da própria administração pública.

Todos esses fatores relatados nos parágrafos anteriores merecem atenção quando se busca compreender o processo de implementação da Lei de Acesso à Informação no Brasil. No Poder Executivo Federal brasileiro, é função da Controladoria-Geral da União o papel de protagonista na definição das políticas e no monitoramento (parcialmente partilhado com o Ministério do Planejamento, Orçamento e Gestão) das ações relativas à Lei de Acesso à Informação, conforme o Decreto n 7.724, de 16 de maio de 2012, que regulamenta a Lei de Acesso à Informação no âmbito do Poder Executivo Federal (BRASIL, 2012).

Entretanto, apesar de o Decreto $\mathrm{n}^{\circ}$ 7.724, de 16 de maio de 2012, estabelecer competências relevantes para a CGU em termos de política e gestão da informação governamental, a CGU não é, até o momento, um órgão com competências e servidores especializados na gestão da informação, como ocorre em agências de informação especializadas (JARDIM, 2012). Muitos obstáculos ainda precisam ser superados pelo governo brasileiro para que o acesso à informação seja uma realidade.

Porém, o governo brasileiro reconhece esses desafios. A pesquisa da Controladoria-Geral da União (BRASIL, 2011b) para a CGU identificou desafios relativos à mudança da cultura do segredo para uma cultura do acesso e também os obstáculos operacionais e técnicos. Os resultados mostraram que as práticas da administração são bastante diversas no que tange à gestão de informações. Enquanto algumas áreas já possuem sistemas de informação e bancos de dados modernos, processos digitalizados, sistemas e vários canais de comunicação com a sociedade, outras ainda estão na era do papel, enfrentando dificuldades para localizar documentos, sistematizar informações básicas e controlar o fluxo de pedidos e de respostas. Uniformizar essa realidade exigirá recursos financeiros e recursos humanos, sobretudo na área de Tecnologia da Informação. 
Assim, embora existam leis que garantem o acesso às informações públicas, estas são disseminadas de forma dispersa e com baixa utilização pela sociedade. Elas ainda são recursos pouco explorados, devido à dificuldade de busca, processamento e reutilização (RIBEIRO; PEREIRA, 2015).

\section{Metodologia}

A presente pesquisa adotou uma abordagem qualitativa, segundo a perspectiva defendida por Gil (2008) e Godoy (1995).

Quanto aos procedimentos metodológicos, trata-se de pesquisa bibliográfica e documental, por meio de um levantamento de informações e referências em artigos, livros, normas de organizações internacionais, leis, decretos e portarias governamentais nacionais, com o intuito de apresentar a gênese e a evolução do VCGE e de como este se construiu como um instrumento de auxilio à transparência e acesso à informação pública.

Na segunda etapa da pesquisa fez-se: i) um levantamento de informações via governo eletrônico, nos portais do governo federal brasileiro sobre o VCGE; e ii) uma consulta à CGU por meio do e-SIC, Sistema Eletrônico do Serviço de Informações ao Cidadão.

A consulta à CGU foi realizada no dia 10 de junho de 2014, sob o número do protocolo 23480.007367/2014-16, com objetivo de verificar a existência de estratégias de preparação prévia dos gestores públicos sobre a classificação e uso do VCGE no sistema e-SIC.

Os portais pesquisados para o levantamento de informações para este artigo foram: Acesso à Informação (2017), Governo Eletrônico (2017), Ministério da Transparência e Controladoria-Geral da União (2017), Portal Brasil (2017), Portal da Transparência (2017), Repositório de Vocabulários e Ontologias do Governo Eletrônico (2017).

\section{Resultados e discussão: contribuições e limites do vocabulário controlado do Governo Eletrônico}

Considerando os objetivos do presente artigo e tendo em vista os dados levantados na pesquisa, apresentaremos, nesta seção a evolução do VCGE, isto 
é, suas diferentes versões ao longo do período, bem como a análise acerca da formação dos gestores públicos para o uso desse instrumento.

\subsection{A evolução do vocabulário controlado do Governo Eletrônico}

A análise da evolução do VCGE apresentada nesta seção teve como objetivo verificar se a evolução na divisão dos principais assuntos e funções de governo trouxe contribuições para implementação da Lei de Acesso à Informação e também se há limitações que podem necessitar de futuras revisões.

Deve-se ressaltar que apesar de algumas categorias do VCGE coincidirem com as funções de governo dos ministérios brasileiros, elas não englobam todas as áreas do governo contempladas por esses ministérios. À época da realização desta pesquisa, o poder executivo federal brasileiro era composto por trinta e nove ministérios, considerando as secretarias da presidência e os órgãos com status de ministério, sendo cada um desses ministérios responsável por um assunto e área específica.

Ressalta-se ainda, que no portal do governo brasileiro, Portal Brasil (2016), os assuntos estão divididos somente em doze áreas, sendo elas: (1) Cidadania e Justiça; (2) Ciência e Tecnologia; (3) Cultura; (4) Defesa e Segurança; (5) Economia e Emprego; (6) Educação; (7) Esporte; (8) Governo; (9) Infraestrutura; (10) Meio Ambiente; (11) Saúde e (12) Turismo.

Apesar de considerar que a questão do número de ministérios no país é importante e deva ser examinada posteriormente, essa pesquisa limitou-se a analisar as categorias do VCGE com o objetivo de apresentar uma reflexão sobre as contribuições e limitações para a aplicabilidade da Lei de Acesso à Informação no Brasil.

Como descrito anteriormente, o VCGE teve inicio com a versão de março de 2004, com a nomenclatura Lista de categorias do Governo, LCG, passando pela versão de 2006, com o nome de Lista para Assuntos do Governo, LAG, seguida das versões de 2011, 2013 e 2014, já na nomenclatura de Vocabulário Controlado do Governo Eletrônico. Assim, o VCGE é uma evolução das listas LCG e LAG, com incorporações de novos termos e correção de inconsistências identificadas. 
O Quadro 3 a seguir apresenta a evolução do vocabulário controlado do governo eletrônico seguida de um breve histórico explicativo das alterações.

Quadro 3 - Evolução do vocabulário controlado do Governo Eletrônico (VCGE)

\begin{tabular}{|c|c|c|}
\hline Ano & Mês & Histórico \\
\hline 2004 & Março & $\begin{array}{l}\text { Criada a Lista de Categorias do Governo, LCG. Uma lista de } \\
\text { termos (indexadores) objetivando a simplificação da busca } \\
\text { de informações pelos usuários. Uma meta primordial dos } \\
\text { Governos da Era da Informação. }\end{array}$ \\
\hline 2006 & Março & $\begin{array}{l}\text { Lançamento da versão Zero da Lista para Assuntos do } \\
\text { Governo (LAG): Taxonomia para Navegação. }\end{array}$ \\
\hline 2010 & Novembro & $\begin{array}{l}\text { Consulta Pública para o VCGE - Vocabulário controlado de } \\
\text { Governo Eletroeletrônico - publicado no DOU. }\end{array}$ \\
\hline 2011 & Março & $\begin{array}{l}\text { Publicação do VCGE - Vocabulário controlado de Governo } \\
\text { Eletroeletrônico }\end{array}$ \\
\hline 2013 & Outubro & $\begin{array}{l}\text { Lançada a versão Outubro } 2013 \text { - } 2.0 \\
\text { Essa versão foi refeita em julho de } 2013 \text { tomando como base } \\
\text { o VCGE anterior, o COFOG e a Portaria } 42 \text {. }\end{array}$ \\
\hline 2013 & Novembro & $\begin{array}{l}\text { Lançada a versão novembro } 2013 \text { - } 2.0 .1 \\
\text { Foi alterada a codificação numérica. Não há alteração nos } \\
\text { termos. Essa versão renumera os termos para uma melhor } \\
\text { adequação ao Decreto } 7.845 \text { de } 2012 \text {. }\end{array}$ \\
\hline 2013 & Dezembro & $\begin{array}{l}\text { Lançada a versão dezembro } 2013-2.0 .2 \\
\text { Apenas para incluir URIs. }\end{array}$ \\
\hline 2014 & Maio & $\begin{array}{l}\text { Lançada a versão Maio } 2014 \text { - } 2.0 .3 \\
\text { Correções em "termos limpos". Havia termos com acentos e } \\
\text { termos fora de ordem. }\end{array}$ \\
\hline
\end{tabular}

Fonte: Adaptado de Ministério do Planejamento, Orçamento e Gestão (BRASIL, 2011c, 2013b e 2014a).

Após sua criação com a nomenclatura VCGE, na primeira versão, publicada em março de 2011, houve uma continuidade das numerações, iniciando com a versão de outubro (2.0), depois a de novembro (2.0.1) e dezembro (2.0.2) de 2013, e a versão atual, de maio de 2014 (2.0.3).

Sobre a periodicidade de versões do VCGE, ressalta-se que estas são geradas sob demanda, quando há alterações, acertos, inclusões e exclusões. Porém, segundo a Secretaria de Logística e Tecnologia da Informação do 
Ministério do Planejamento, Orçamento e Gestão (BRASIL, 2014a), é feito um esforço para agrupar essas versões de forma que não haja mais de uma por mês.

Foi realizada, ainda, uma análise da primeira versão com a nomenclatura VCGE e da versão mais atual. O resultado da análise das versões de 2011 e 2014 (versão 2.0.3) mostra o surgimento de seis novos níveis gerais que surgiram ainda em 2013 na versão 2.0.2, sendo que a versão 2011 apresentava 17 categorias e a versão 2013, 23 categorias. Algumas categorias foram desmembradas e outras foram criadas (Administração, Energia, Previdência Social, Proteção social). As categorias excluídas foram: Governo e Política; Justiça e Legislação; Pessoa, família e sociedade. Termos que eram partes de outras categorias também foram retirados do nível 1, excluídos ou substituídos, são eles: Ciência, Informação e Turismo.

A versão do VCGE 2011 foi apresentada de forma completa até o $5^{\circ}$ nível para algumas categorias, mas a versão mais atual, de maio de 2014 (2.0.3), assim como as versões anteriores de 2013 , somente atinge o $2^{\circ}$ nível para todas as categorias.

As diferenças entre as versões de março de 2011 e a ultima versão de maio de 2014, no que se refere ao nível geral ou primeiro nível, são apresentadas no Quadro 4.

Quadro 4 - Apresentação das categorias do primeiro nível das versões de 2011 e 2014 do VCGE

\begin{tabular}{|l|l|l|}
\hline Versão março de 2011: & $\begin{array}{l}\text { 1. Agricultura, extrativismo e pesca; 2. Ciência, Informação e } \\
\text { Apresentação do Primeiro } \\
\text { Nível do VCGE }\end{array}$ & $\begin{array}{l}\text { e Esporte; 5. Defesa e Segurança; 6. Economia e Finanças; } 7 . \\
\text { Educação; 8. Governo e Política; 9. Habitação, Saneamento e }\end{array}$ \\
$\begin{array}{l}\text { Urbanismo; 10. Indústria; 11. Justiça e Legislação; 12. Meio } \\
\text { ambiente; 13. Pessoa, família e sociedade; 14. Relações } \\
\text { internacionais; 15. Saúde; 16. Trabalho; 17. Transportes e trânsito. }\end{array}$ \\
\hline $\begin{array}{l}\text { Versão maio de 2014: } \\
\text { Apresentação do Primeiro } \\
\text { Nível do VCGE }\end{array}$ & $\begin{array}{l}\text { 1. Administração; 2. Agropecuária; 3. Comércio e Serviços; } 4 . \\
\text { Comunicações; 5. Cultura; 6. Defesa Nacional; 7. Economia e } \\
\text { Finanças; 8. Educação; 9. Energia; 10. Esporte e Lazer; } 11 . \\
\text { Habitação; 12. Indústria; 13. Meio ambiente; 14. Pesquisa e } \\
\text { Desenvolvimento; 15. Previdência Social; 16. Proteção social; } 17 . \\
\text { Relações internacionais; 18. Saneamento; 19. Saúde; } 20 . \\
\text { Segurança e Ordem Pública; 21. Trabalho; 22. Transportes; } 23 . \\
\text { Urbanismo. }\end{array}$ \\
\hline
\end{tabular}

Fonte: Ministério do Planejamento, Orçamento e Gestão, Secretaria de Logística e Tecnologia da Informação (BRASIL, 2011c, 2013b e 2014a). 
Um estudo realizado por Jardim (2007) sobre o portal Rede Governo, no período de maio de 2003 a março de 2005, identificou a classificação de categorias utilizadas pelo governo federal na época. A classificação contemplava duas grandes áreas: serviços e informações, subdivididas em 36 categorias, apresentadas no Quadro 5.

Quadro 5 - Apresentação das categorias utilizadas na classificação do portal Rede Governo

\begin{tabular}{|c|c|c|}
\hline Agricultura & Economia e Finanças & Notícias \\
\hline Assistência Social & Educação & Oportunidades de trabalho \\
\hline Centrais de atendimento & Emprego e Trabalho & Previdência Social \\
\hline Cidadania & Esportes & Publicações Oficiais \\
\hline Ciência e tecnologia & Fale Conosco & Recursos Energéticos \\
\hline Comércio & Fisco & Recursos Minerais \\
\hline Comunicações & Glossários & Saúde \\
\hline Correios & Indústria & Segurança Pública \\
\hline Cultura & Justiça & Serviços diplomáticos \\
\hline Defesa & Legislativo & Servidor Público \\
\hline Denúncias & Licitações & Transporte \\
\hline Direitos Humanos & Meio Ambiente & Turismo \\
\hline
\end{tabular}

Fonte: Jardim (2007).

Nota-se que a classificação utilizada pelo governo federal à época era mais detalhada nas categorias de segundo nível e abrangia temas hoje já incorporados nas páginas iniciais dos portais do governo, como: Fale Conosco, Glossários e Publicações Oficiais. Essa evolução na classificação propiciou facilidade ao acesso da sociedade a esse tipo de informação que se tornou mais acessível, sendo uma contribuição e um avanço na classificação dessas categorias.

Sobre a classificação utilizada no vocabulário controlado do governo eletrônico, a evolução das versões dessa ferramenta, após a edição da Lei de Acesso à Informação, sugere um esforço do governo federal, por meio das 
equipes envolvidas em avançar na melhoria da classificação das funções do governo. Prova disso são as revisões contínuas seguidas de consultas públicas, workshop, debates e reuniões abertas para interessados em contribuir com o trabalho da equipe responsável. Parece indicar, também, que as demandas da sociedade por informações que não se ajustam aos termos definidos nas diversas versões do VCGE tenham impulsionado as mudanças.

Uma comparação do detalhamento do VCGE com a classificação das funções de governo internacional, COFOG, mostra que o nível de detalhamento do vocabulário controlado do governo eletrônico é somente de dois níveis enquanto a classificação COFOG apresenta três níveis: Divisão, Grupo e Classe. Sendo que as Divisões descrevem os objetivos gerais do governo, enquanto os grupos e classes definem os meios pelos quais estes grandes objetivos são alcançados. Assim, parece que a classificação internacional tem maior profundidade no que tange os temas e assuntos classificados. O que pode ser uma limitação do VCGE, que possui menor profundidade com seus dois níveis.

\subsection{Análise sobre a preparação dos gestores públicos para o uso do VCGE: resposta da Controladoria-Geral da União}

No dia 10 de junho de 2014, sob o número do protocolo 23480.007367/2014-16, uma das autoras deste artigo perguntou à Controladoria-Geral da União, se havia uma preparação prévia dos gestores públicos sobre a classificação e uso do vocabulário controlado do governo eletrônico no sistema e-SIC.-A CGU respondeu não terem sido "realizados treinamentos específicos" para preenchimento do VCGE ao mesmo tempo em que afirmou considerar que "as orientações disponibilizadas pelo Ministério do Planejamento no documento descritivo do VCGE são suficientes para o seu entendimento pelos servidores responsáveis pelo preenchimento via sistema e-SIC."

Assim, apesar da relevância do uso do VCGE na classificação das demandas por informações públicas no sistema e-SIC e apesar de a CGU ter um papel importante na implementação da $\mathrm{LAI}^{3}$, no que se refere ao desenvolvimento de práticas relacionadas à transparência na administração 
pública, em alguns aspectos, como o do treinamento para o uso desse instrumento de classificação, o órgão parece não corresponder.

Em sua pesquisa de doutorado sobre a implantação da LAI nas universidades federais brasileiras, Gama (2015) ratifica o entendimento sobre a existência de dificuldades por parte dos gestores que necessitam utilizar o VCGE para classificação de suas informações no e-SIC. A referida autora constatou que gestores da universidade analisada não receberam treinamento sobre como classificar as informações nas categorias e subcategorias do VCGE. Em várias universidades federais foi verificado que a categoria "Educação" abrange a quase totalidade das demandas indicadas, com pouquíssimo uso de outras classificações, apesar do estudo identificar, por exemplo, que o aumento nas demandas por informações contábeis, financeiras e orçamentárias, a partir do terceiro ano em relação ao primeiro ano de implementação da LAI, supera o aumento registrado nas demandas das categorias gerais em quase $15 \%$ nessas instituições. Esse resultado parece, de fato, sugerir falta de conhecimento ou mesmo falha na classificação.

Ainda na pesquisa de Gama (2015), segundo a resposta de um gestor público, participante do estudo e responsável pela operacionalização desse sistema numa universidade federal, ele afirma que apesar de ter recebido treinamento para uso do sistema e-SIC por parte do governo, ele encontra problemas em utilizar o VCGE para classificar as demandas de informações nesse sistema já que não recebeu nenhum treinamento especifico sobre essa ferramenta.

Pode-se, então, perceber que a despeito do governo brasileiro ter planejado a realização de treinamento dos servidores federais para implementação da LAI e uso do e-SIC, o mesmo cuidado não foi constatado em relação ao uso da ferramenta de classificação do VCGE.

Assim, os gestores públicos responsáveis pelo registro da demanda por informações públicas no sistema e-SIC, após a edição da LAI, contam somente com a ajuda das cartilhas elaboradas pelo governo federal, apesar de ser um dos objetivos do VCGE servir como ferramenta de gestão para esses gestores públicos. 


\section{Considerações finais}

Esse artigo teve como objetivo identificar a contribuição e os limites do vocabulário controlado do Governo Eletrônico na implementação da Lei de Acesso à Informação na Administração pública federal brasileira. Nos limites a serem observados, estavam a identificação de ações da Controladoria-Geral da União no sentido de preparar os gestores públicos para a utilização dessa ferramenta.

A finalidade do vocabulário controlado do Governo Eletrônico é classificar qualquer conteúdo de informação, como documentos em papel, bases de dados e mídia eletrônica, que não seja classificado por outra forma mais específica de indexação, pois estes já são realizados por meio de vocabulários especializados. O vocabulário controlado do Governo Eletrônico foi elaborado para ser consultado pelo público geral, sem necessidade de conhecimento especializado como os de bibliotecários e arquivistas, o que nesse aspecto, parece ser uma contribuição para seus usuários.

Ainda em relação às contribuições, pode-se afirmar que com o advento da Lei de Acesso a Informação, o vocabulário controlado do Governo Eletrônico assumiu uma função relevante, de classificar as demandas pelo Sistema de Informação ao Cidadão da Controladoria-Geral da União, e-SIC. Além de atingir todos os órgãos do poder executivo que respondiam às demandas, o uso da classificação no sistema e-SIC confirmou um dos aspectos relevantes do vocabulário controlado do governo eletrônico: interface com o cidadão.

O sistema e-SIC objetiva funcionar como porta de entrada única para os pedidos de informação, a fim de organizar e facilitar o processo, tanto para o cidadão quanto para os órgãos da administração pública. Inclusive os pedidos feitos pessoalmente por meio dos Serviços de Informações ao Cidadão, instalado fisicamente em todos os órgãos e entidades do governo federal, também deverão ser registrados no sistema e-SIC. Assim, todas as demandas da sociedade após a entrada em vigor da LAI são classificadas nesse sistema com a utilização do vocabulário controlado do governo federal.

Porém, cabe ressaltar que apesar de pertinente a preocupação do governo em elaborar uma classificação que possa ser usada por cidadãos das mais 
diversas classes sociais, a maior parte dos demandantes que entram com pedidos de informação para o governo, bem como os gestores que utilizam o sistema eSIC, possuem nível superior ou mesmo mestrado e doutorado.

Já sobre a evolução das versões do vocabulário controlado do governo eletrônico, após a edição da Lei de Acesso à Informação, pode-se notar um esforço por parte do governo federal em avançar na melhoria da classificação das funções do governo. Porém, a consulta à Controladoria-Geral da União por meio do e-SIC aponta que até o momento dessa pesquisa não houve nenhum treinamento oferecido aos gestores públicos no uso dessa ferramenta, o que pode ser uma limitação para operacionalização da Lei de Acesso à Informação por meio do sistema e-SIC.

Portanto, apesar de ser um dos objetivos do vocabulário controlado do governo eletrônico servir como ferramenta de gestão para os gestores públicos, é incoerente com esse objetivo constatar que, na prática, os gestores públicos responsáveis pelo registro da demanda por informações públicas após a edição da Lei de Acesso à Informação no e-SIC, não tiveram nenhum treinamento, contando somente com a ajuda das cartilhas e manuais elaborados pelo governo federal. Assim, sua operacionalização como ferramenta de gestão está limitada pelos materiais publicados pela Controladoria-Geral da União.

Este artigo concorda com a posição de Ribeiro e Pereira (2015) quando estes afirmam que muitos desafios ainda precisam ser vencidos em relação a vocabulários controlados na administração pública, como “[...] a ausência de modelos conceituais, a inexpressiva cooperação entre as áreas públicas para compartilhamento de experiências, a falta de semântica entre os dados e a ineficaz divulgação dos dados já publicados.” (RIBEIRO; PEREIRA, 2015, p. $81)$.

Isso pode ser confirmado com uma comparação com a classificação das funções de governo internacional, COFOG, que mostra que o nível de detalhamento do vocabulário controlado do governo eletrônico é somente de dois níveis enquanto a classificação COFOG apresenta três níveis, Divisão, Grupo e Classe. Ou seja, a classificação internacional apresenta maior profundidade no que tange os temas e assuntos classificados, permitindo que os 
usuários, servidores e gestores públicos, possam usufruir mais detalhes para classificar suas demandas nas categorias corretas. O que pode ser também uma limitação do vocabulário controlado do governo eletrônico.

Deve-se ressaltar que a Lei de Acesso à Informação, apesar de ter completado cinco anos, ainda carece de uma análise mais profunda quanto à utilização dessa ferramenta de classificação. Estudos envolvendo os usuários do sistema e-SIC, poderiam, por exemplo, esclarecer se há necessidade de essa ferramenta ter seus níveis de classificação mais aprofundados por parte do governo federal.

\section{Referências}

ACESSO à Informação. [2017]. Disponível em: <http://www.acessoainformacao.gov.br/>. Acesso em: 23 ago. 2017.

ALMEIDA, Tatiana; SOUZA, Rosali Fernandes. O vocabulário controlado como instrumento de organização e representação da informação na FINEP. In. ENCONTRO NACIONAL DE PESQUISA EM CIÊNCIA DA INFORMAÇÃO, 12., 2011, Brasília. [Trabalhos apresentados]. Brasília, 2011.

BACHA, Márcia Nunes; ALMEIDA, Maria do Socorro G. de. Vocabulário controlado e palavras-chave em repositórios digitais: relato de experiência do repositório institucional da FGV. In. CONGRESSO BRASILEIRO DE BIBLIOTECONOMIA, DOCUMENTO E CIÊNCIA DA INFORMAÇÃO, 25. 2013, Florianópolis. Anais... Florianópolis, 2013.

BRASIL. Constituição da República Federativa do Brasil de 1988. 1988. Disponível em:

<http://www.planalto.gov.br/ccivil_03/constituicao/constituicao.htm>. Acesso em: 22 ago. 2017.

BRASIL. Controladoria-Geral da União. Secretaria de Prevenção da Corrupção e Informações Estratégicas. Guia técnico de regulamentação da Lei de Acesso à Informação em municípios e check list. Brasília, 2013a. Disponível em: <http://www.cgu.gov.br/Publicacoes/transparencia-publica/brasiltransparente/arquivos/guia_checklist.pdf>. Acesso em: 30 nov. 2014.

BRASIL. Controladoria-Geral da União. Sumário executivo: pesquisa diagnóstico sobre valores, conhecimento e cultura de acesso à informação pública... Brasília, 2011b. Disponível em:

<http://www.acessoainformacao.gov.br/central-deconteudo/publicacoes/pesquisadiagnostico.pdf>. Acesso em: 17 maio 2014. 
BRASIL. Decreto $n^{\circ} 7.724$, de 16 de maio de 2012. Regulamenta a Lei $n^{\circ}$ 12.527, de 18 de novembro de 2011, que dispõe sobre o acesso a informações previsto no inciso XXXIII do caput do art. $5^{\circ}$, no inciso II do $\S 3^{\circ}$ do art. 37 e no $\S 2^{\circ}$ do art. 216 da Constituição. Diário Oficial da União, Brasília, 16 maio 2012. Seção 1, p. 1. Disponível em: <http://www.planalto.gov.br/ccivil_03/_ato20112014/2012/decreto/d7724.htm>. Acesso em: 20 jul. 2014.

BRASIL. Lei $\mathrm{n}^{\circ}$ 12.527, de 18 de novembro de 2011. Regula o acesso a informações previsto no inciso XXXIII do art. $5^{\circ}$, no inciso II do $\S 3^{\circ}$ do art. 37 e no $\S 2^{\circ}$ do art. 216 da Constituição Federal; altera a Lei no 8.112, de 11 de dezembro de 1990; revoga a Lei $n^{\circ} 11.111$, de 5 de maio de 2005, e dispositivos da Lei $\mathrm{n}^{\circ} 8.159$, de 8 de janeiro de 1991; e dá outras providências. Diário Oficial da União, Brasília, 18 nov. 2011a. Seção 1, p. 1. Disponível em: <http://www.planalto.gov.br/ccivil_03/_ato2011-2014/2011/lei/112527.htm>. Acesso em: 5 jul. 2014.

BRASIL. Ministério do Orçamento e Gestão. Portaria no 42, de 14 de abril de 1999. Atualiza a discriminação da despesa por funções de que tratam o inciso I, do $\S 1^{\circ}$, do art. $2^{\circ}$, e $\S 2^{\circ}$, do art. $8^{\circ}$, ambos da Lei $n^{\circ} 4.320$, de 17 de março de 1964; estabelece conceitos de função, subfunção, programa, projeto, atividade, operações especiais e dá outras providências. 1999. Disponível em:

<http://www.orcamentofederal.gov.br/orcamentos-anuais/orcamento1999/Portaria_Ministerial_42_de_140499.pdf/>. Acesso em: 22 ago. 2017.

BRASIL. Ministério do Planejamento, Orçamento e Gestão. Secretaria de Logística e Tecnologia da Informação. VCGE: Vocabulário de Governo Eletrônico. Brasília, 2011c.

BRASIL. Ministério do Planejamento, Orçamento e Gestão. Secretaria de Logística e Tecnologia da Informação. VCGE: Vocabulário de Governo Eletrônico. Brasília, 2013b.

BRASIL. Ministério do Planejamento, Orçamento e Gestão. Secretaria de Logística e Tecnologia da Informação. VCGE: Vocabulário de Governo Eletrônico. Brasília, 2014a.

EUROSTAT. Glossary: classification of the functions of government (COFOG). 2014. Disponível em:

<http://epp.eurostat.ec.europa.eu/statistics_explained/>. Acesso em: 21 out. 2014.

GAMA, Janyluce Rezende. Instrumentos de transparência e acesso às informações públicas: um estudo das demandas por informações contábeis nas universidades federais. 2015. Tese (Doutorado em Ciência da Informação) Universidade de Brasília, Brasília, 2015. Disponível em: <http://repositorio.unb.br/handle/10482/19201>. Acesso em: 20 dez. 2016. 
GARRIDO, Elena Pacita Lois. Lei de acesso às informações públicas. Revista Jurídica CNM, Brasília, v. 1, n. 1, p. 50-70, 2012. Disponível em:

<http://www.leideacesso.cnm.org.br/leideacesso/pdf/Artigo_LeideAcessoInform acao.pdf>. Acesso em: 6 out. 2014.

GIL, Antonio Carlos. Métodos e técnicas de pesquisa social. 6. ed. São Paulo: Atlas, 2008.

GODOY, Arilda Schimidt. Introdução à pesquisa qualitativa e suas possibilidades. Revista de Administração de Empresas, São Paulo, v. 35, n. 2, p. 57-63, mar./abr. 1995.

GONTIJO, Miriam. Análise da proposta brasileira de E-Governo como expressão de uma política de informação a partir do conceito de regime de informação. Perspectivas em Ciência da Informação, Belo Horizonte, v. 7, n. 2, p. 179-188, jul./dez. 2002. Disponível em:

<http://portaldeperiodicos.eci.ufmg.br/index.php/pci/article/view/406>. Acesso em: 2 dez. 2014.

GOVERNO Eletrônico. [Brasília, 2017]. Disponível em:

<https://www.governoeletronico.gov.br/>. Acesso em: 23 ago. 2017.

\section{INTERNATIONAL MONETARY FUND. Government finance statistics} manual 2014. Washington, 2014. Disponível em:

<http://www.imf.org/external/np/sta/gfsm/pdf/text14.pdf >. Acesso em: 2 dez. 2014.

JARDIM, José Maria. A implantação da lei de acesso à informação pública e a gestão da informação arquivística governamental. Liinc em Revista, Rio de Janeiro, v. 9, n. 2, p. 383-405, nov. 2013. Disponível em: <http://revista.ibict.br/liinc/article/view/3495>. Acesso em: 5 out. 2014.

JARDIM, José Maria. Governo eletrônico no Brasil: o Portal Rede Governo. Arquivística.net, Rio de janeiro, v. 3, n. 1, p. 28-37, jan./jun. 2007. Disponível em: <http://www.egov.ufsc.br/portal/sites/default/files/anexos/30773-32930-1PB.pdf>. Acesso em: 6 maio 2015.

JARDIM, José Maria. Lei de acesso à informação pública: dimensões políticoinformacionais. Tendências da Pesquisa Brasileira em Ciência da Informação, Salvador, v. 5, n. 1, 2012. Disponível em: <http://inseer.ibict.br/ancib/index.php/tpbci/article/view Article/68>. Acesso em: 2 ago. 2014.

LOPES, Ilza Leite. Uso das linguagens controlada e natural em bases de dados: revisão da literatura. Ciência da Informação, Brasília, v. 31, n. 1, p. 41-52, jan./abr. 2002. 
MENDEL, Toby. Freedom of information: a comparative legal survey. 2nd ed. UNESCO: Paris, 2008. Disponível em:

<http://unesdoc.unesco.org/images/0015/001584/158450e.pdf>. Acesso em: 10 mar. 2013.

MINISTÉRIO da Transparência e Controladoria-Geral da União. [Brasília, 2017]. Disponível em: 〈http://www.cgu.gov.br/>. Acesso em: 23 ago. 2017.

MORAES, Juliana de Souza et al. Plano de inovação para o vocabulário controlado do SIBiUSP: relato de experiência. SEMINÁRIO NACIONAL DE BIBLIOTECAS UNIVERSITÁRIAS, 17., 2012, Gramado. Anais... Porto Alegre, 2012. Disponível em: 〈http://eprints.rclis.org/17885/>. Acesso em: 13 abr. 2015.

NARUKAWA, Cristina Miyuki. Estudo de vocabulário controlado na indexação automática: aplicação no processo de indexação do Sistema de Indización SemiAutomatica (SISA). 2011. Dissertação (Mestrado em Ciência da Informação) - Faculdade de Filosofia e Ciências, Universidade Estadual Paulista, Marília, 2011.

NOGUEIRA, Ronaldo Alves; CAVALCANTE, Pedro. Quanto custa o estado de bem-estar brasileiro? [2010]. Disponível em:

<http://www.esaf.fazenda.gov.br/premios/premios-1/premios-realizados/pastapremio-artigos-cientificos-informacao-de-custos-e-qualidade-do-gasto-no-setorpublico/resultado-e-trabalhos-premiados>. Acesso em: 5 fev. 2015.

ORGANISATION FOR ECONOMIC CO-OPERATION AND

DEVELOPMENT. Classification of the functions of government (COFOG). In: ORGANISATION FOR ECONOMIC CO-OPERATION AND DEVELOPMENT. Governo at a glance 2011. [Paris]: OCDE Publishing, 2011. p. 194-195. Disponível em: 〈http://www.oecd.org/gov/48250728.pdf〉. Acesso em: 21 out. 2014.

PORTAL Brasil. [Brasília, 2017]. Disponível em: <http://www.brasil.gov.br/>. Acesso em: 23 ago. 2017.

PORTAL da Transparência. [Brasília, 2017]. Disponível em: <http://www.portaltransparencia.gov.br/>. Acesso em: 23 ago. 2017.

REPOSITÓRIO de Vocabulários e Ontologias do Governo Eletrônico. Disponível em: <http://vocab.e.gov.br/>. Acesso em: 23 ago. 2017.

RIBEIRO, Cláudio José Silva; PEREIRA, Durval Vieira. A publicação de dados governamentais abertos: proposta de revisão da classe sobre previdência social do vocabulário Controlado do Governo Eletrônico. TransInformação, Campinas, v. 27, n. 1, p. 73-82, jan./abr. 2015. Disponível em: <http://www.scielo.br/pdf/tinf/v27n1/0103-3786-tinf-27-01-00073.pdf>. Acesso em: 5 maio 2015. 
SEVAROLLI, Ivany; MENDES, Ricardo. Vocabulário controlado para acervos fotográficos: iniciativa e desenvolvimento no Arquivo Histórico de São Paulo. Revista CPC, São Paulo, n. 17, p. 1-27, nov. 2013/abr. 2014.

SIQUEIRA, Jessica Camara. Recursos linguísticos para análise de vocabulário controlado: o caso do SAUSP. Biblionline, João Pessoa, v. 7, n. 2, p. 52-62, 2011. Disponível em:

<http://www.ies.ufpb.br/ojs/index.php/biblio/article/view/10211>. Acesso em: 2 fev. 2015.

SILVA, Bruna; DODEBEI, Vera Lucia Louzada. Vocabulário de termos livres e controlados para a coleção de teses e dissertações da Universidade Federal de Viçosa. In: ENCONTRO NACIONAL DE PESQUISA EM CIÊNCIA DA INFORMAÇÃO, 17., 2016, Salvador. Anais... Salvador: UFBA, 2016.

SMIT, Johanna Wilheumina; KOBASHI, Nair Yumiko. Como elaborar vocabulário controlado para aplicação em arquivos. São Paulo: Imprensa Oficial do Estado de São Paulo, 2003. (Como fazer, v.10).

SPECK, Bruno Wilhelm (Org.). Caminhos da transparência. Campinas: Unicamp, 2002.

\title{
Controlled Vocabulary of Electronic Government: contribution and limits in implementing the Access to Information Act in \\ Brazil
}

\begin{abstract}
The law on access to information, enacted in 2011, introduced a system, allowing that all information requests are made through a single input, regardless of the recipient. This system classifies and organizes the requests using a controlled vocabulary facilitating the process, for citizens and for public managers. The aim is to verify the contribution and limits of the Controlled Vocabulary of the Electronic Government in the implementation of the law on access to information in the Federal Public Administration. For this, an analysis of the evolution of this tool was made. In addition, it was investigated in agencies of the federal government how was the preparation of public officials to use this tool. A methodology with a qualitative approach was used, in the first stage, involving a literature research and collecting information on the websites of the federal government, and in the second, involving a consultation to the Comptroller General of the Union. The results point to an effort by the federal government in improving the classification of government functions to classify the demands arising from the law on access to information. However, the consultation to the Comptroller General showed that until moment of the
\end{abstract}


consultation, there was no training of public managers in the use of controlled vocabulary as a management tool. It was found also that there was a contribution of this tool when it took a relevant role in the classification of demands by the Citizens Information System that encompasses all agencies of the federal executive power.

Keywords: Access to Information Act. Controlled language. Controlled Vocabulary of Electronic Government. Transparency. Public Government.

Recebido em: 01/02/2017

Aceito em: 26/07/2017

1 LANCASTER, F. W. Indexação e resumos: teoria e prática. 2. ed. Brasília: Briquet de Lemos, 2004. Apud Silva e Dodebei (2016).

2 Controladoria-Geral da União. Mensagem recebida por Janyluce Gama em 10/06/2014. Conforme protocolo $\mathrm{n}^{\circ}$. 23480.007367/2014-16.

3 O órgão tem suas competências expressas na Lei 12.527, de 11 de novembro de 2011 e no Decreto $n^{\circ} 7.724$, de 16 de maio de 2012 para, entre outras, promover o treinamento dos agentes públicos e, no que couber, a capacitação das entidades privadas sem fins lucrativos (BRASIL, 2012). 